\title{
Recycling and Utilization of Waste Glass Fiber Reinforced Plastics
}

\author{
FENG Yan-chao ${ }^{1}$, ZHAO Feng-qing ${ }^{1,2 *}$ and XU Hong ${ }^{1,3}$ \\ ${ }^{1}$ Hebei University of Science \& Technology, Shijiazhuang 050018 \\ ${ }^{2}$ Hebei Engineering and Research Center of Solid Waste Utilization, Shijiazhuang, 050018 \\ ${ }^{3}$ Hebei Engineering Research Center of Pharmaceutical and Chemical Engineering, Shijiazhuang \\ 050018, PR China
}

\begin{abstract}
This paper mainly introduced the recovery method, classification and comprehensive utilization process of waste glass fiber reinforced plastics (GFRP). Among the current methods of utilization, the physical method is most promising. After pre-processing of waste GFRP, the short glass fiber can be used in gypsum block to improve the anti-cracking and operation performance of the material; waste GFRP powder can be used in plastic fiber reinforced manhole covers to increase the mechanical strength, and the products conformed to JC 1009-2006. Based on these studies, we also point out some problems concerning the utilization of waste glass fiber reinforced plastics.
\end{abstract}

\section{Introduction}

Glass fiber reinforced plastic is a new type of composite materials made of reinforced materials (mostly use GFRP products) and binders (synthetic resin) by laminating, winding and molding process. It's a material with the features of lightweight, great corrosion protection, good thermal, electrical and sound insulation. The popular name of GFRP was given by Lai Jifa in 1958, who is the building materials industry minister of China at that time. Since then, glass fiber reinforced plastic become widespread in China.

Glass fiber reinforced plastic has been widely used in construction, national defense, energy, transportation, chemical engineering and electronic power owing to the excellent performance of design flexibility, easy formation etc. And the proportion of GFRP in the economic development is increasing.

With the rapid development of economy, the application of GFRP materials is increasingly wider. Meanwhile, quantities of wastes are also increasing rapidly. According to a project, global glass fiber reinforced plastic production has reached 8 million tons annually, but the waste has up to 1.5 million tons and the recycle utilization rate is only $13 \%$. The GFRP industry began to rise in China since the $1950 \mathrm{~s}$. After 50 years of rapid development, glass fiber reinforced plastic obtained the development by leaps and bounds. The annual output of GFRB of China in 2013 amounted to 3.96 million tons, which ranked

* Corresponding author: zhaofq3366@126.com 
the second largest in the world [1]. The characteristics of glass fiber reinforced plastic such as high strength and strong corrosion resistance make recycling and utilization more difficult. Therefore, reasonable processing and application technology of waste glass fiber reinforced plastic become an urgent problem to be solved.

This article mainly studied on the classification and waste disposal technology of glass fiber reinforced plastic, then puts forward a series of proposals to the applications of waste glass fiber reinforced plastic. The recycling of waste glass fiber reinforced plastic played an important role in the development of GFRP. [2,3].

\section{Classification of Waste Glass Fiber Reinforced Plastics}

Waste glass fiber reinforced plastics can be divided into thermoplastics FRP and thermosetting FRP or industrial waste and general waste respectively.

Thermosetting FRP has the advantages of design flexibility, lightweight, high strength, and good corrosion resistance, mainly used for building materials, highway, mining and so on. With the increasing demand for thermosetting FRP, the quantities of waste glass fiber reinforced plastics also has a sharp rise, mainly includes the overage waste, tailings and waste from production and processing. In addition, thermosetting FRP can't be molded again by heating and it is more difficult to recycle thermosetting FRP after painting, coating and used with other plastic parts.

Industrial waste glass fiber reinforced plastics is mainly from the production process and the tailings material, waste and scrap are not polluted. There are three types of glass fiber reinforced plastics resin frequently used: epoxy resin, unsaturated polyester and phenolic resin[4].

\section{Utilization Technology of Waste Glass Fiber Reinforced Plastics}

There are many recycling and utilization methods of waste glass fiber reinforced plastics, and specific recycling method depends on the types and characteristics of the waste. At present, the recycling and utilization methods of waste glass fiber reinforced plastics both at home and abroad are almost the same . Generally speaking, it can be divided into four types: chemical recycling, physical recycling, energy recovery and comprehensive recovery.

\section{Chemical Recycling Method}

Chemical recycling is a method dividing the waste glass fiber reinforced plastics into available fuel (such as gas, fuel oil, etc.) and solid by-products. This method can be used to recycle all types of waste glass fiber reinforced plastics, but it is difficult in technology, expensive and high requirement for recycling equipment.

Pyrolysis recycling is an important kind of chemical recycling method. It convert the waste glass fiber reinforced plastics into pyrolysis oil, cracking gas and solid product [5]in the anaerobic environment by reference of the pyrolysis recycling method of plastics and rubber. The pyrolysis products varies with pyrolysis temperature. For instance, in $400 \sim 500{ }^{\circ} \mathrm{C}$ we obtain pyrolysis oil mainly, in $600 \sim 700{ }^{\circ} \mathrm{C}$ mainly recycling pyrolysis gas. Once the pyrolysis process begins, the temperature will reach $480 \sim 980{ }^{\circ} \mathrm{C}$, and the pyrolysis gas takes enough energy to supply pyrolysis process to achieve self-sufficiency, and the spare parts can be stored to used as fuel. Analyzing the outgoing gas of the pyrolysis process, we can find that the emissions substantially meet the safety and 
environmental requirements and can be directly discharged into the air[6].

The obvious advantage of pyrolysis is that this method can handle waste glass fiber reinforced plastics be polluted by paint, adhesive and other materials. Whereas, it is easy to cause pyrolysis furnace wall damaged due to the poor heat transfer performance of the waste and the serious decomposition of the resin part in high temperature pyrolysis process. Now a new technology using steam as heat source can make the materials heat evenly, promote the thermal decomposition reaction, and protect the pyrolysis furnace wall from being damaged, etc [7].

\section{Physical Recycling Method}

Physical recycling also called crush recycling. This method crush the waste glass fiber reinforced plastics to size-uniformity by coarse crushing machine and then use it as a raw material. Before it applied, it is necessary to study the influence of the addition of waste glass fiber reinforced plastics on new materials, and make experiment to determine the highest percent of it and make sure that there is no adverse impact on the new material performance. Physical recycling method is simple in technology, low cost and most widely used when waste glass fiber reinforced plastics with high purity.

Crush recycling method is best suited for the waste glass fiber reinforced plastics products directly used With no changes in chemical properties. There are two kinds of utilization ways: one is used as functional fillers after the waste crushed into powder; another use the short-fibers as reinforced material [8]. The researches about waste glass fiber reinforced plastics being used as functional filler or reinforcement material in SMC, $\mathrm{BMC}$, etc. are common. Some of them have been applied in practice.

\section{Energy Recycling Method}

Energy recovery is realized by using the organic or partial organic waste as a fuel. Plenty of heat produced in combustion process, transforming the combustion heat to other energy form. Combustion test showed that the waste glass fiber reinforced plastics can burn and also has high calorific value, so it can be used as energy resources.

Energy recycling is one of the simplest means to recycle waste glass fiber reinforced plastics. But it is easy to release toxic gas and smoke to the atmosphere in burning process. In order to avoid this problem, it is necessary to design a high performance incinerator. Inevitably, the measure to increase the recycling cost must be adopted at the same time. In addition, ash also needs to landfill after burning and may cause secondary pollution to the environment.

\section{Application of Waste GFRP in Practice}

\subsection{Reinforced Raw Materials for the Gypsum Products}

The application of the waste glass fiber reinforced plastics as reinforced raw materials in gypsum products is used by cutting the waste material to short fiber of $0.5 \sim 2 \mathrm{~mm}$. This method can increase the tensile strength, which contributed to the resistance to cracking. Besides, this approach can increase the processing properties of gypsum products. See Fig.1 and Fig.2. 

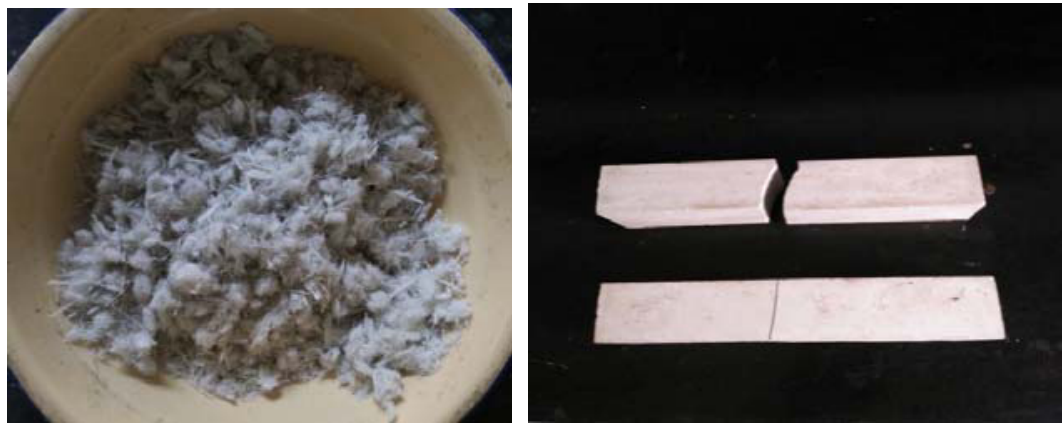

Fig.1 Waste glass fiber.

Fig.2 Block from waste GFRP contained gypsum

Glass fiber has large fracture toughness, and in the fiber reinforced gypsum matrix, the fiber can absorb more energy which inhibits cracking of the gypsum bock.

\subsection{Utilization in Manhole Covers}

The waste GFRP was crushed to short fiber of 3-5 mm, and mixed with some additives, pressured formed to produce glass reinforced plastics manhole cover (DN300 cm in diameter, See Fig.3). Curing in laboratory environment for $25 \mathrm{~h}$, the product made meet JC 1009-2006. The results are shown in table 1 .
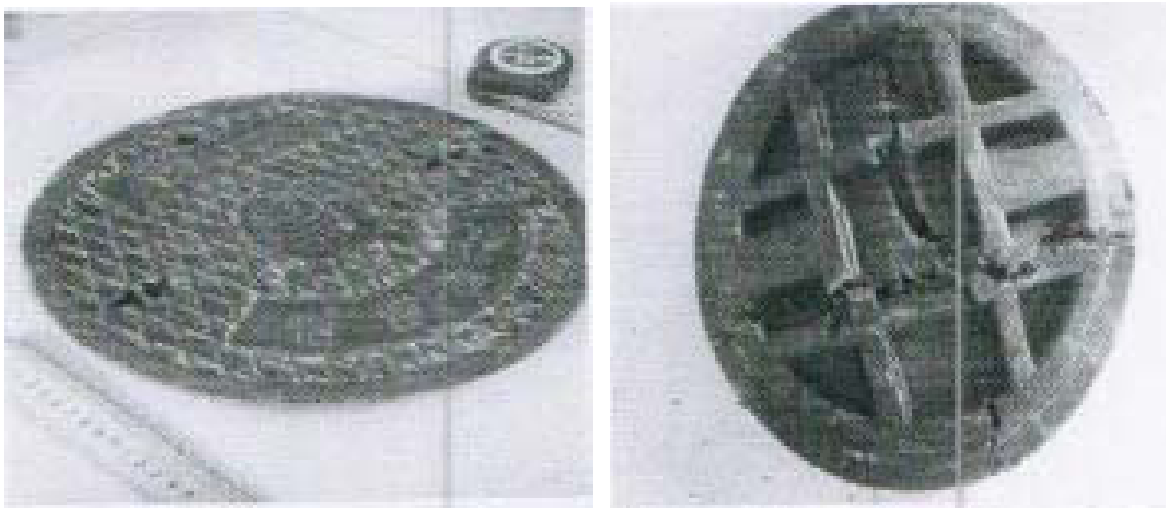

Fig.3 manhole covers made from waste gfrp (before and after loading test)

Table 1 basic performance of the manhole covers

\begin{tabular}{|c|c|}
\hline NO. & Breaking load/KN \\
\hline 1 & 70 \\
\hline 2 & 75 \\
\hline 3 & 61 \\
\hline
\end{tabular}




\subsection{Problems and Measures of the Recycling and Utilization of Waste GFRP.}

Obvious problems exist in the process of crushing glass fiber reinforced plastics. For example, it is difficult to crush the glass fiber reinforced plastics with high strength and high toughness. As the glass fiber reinforced plastics is the cross-linked structure of resin and glass fiber, the crushing energy consumption of the waste is relatively high. It is impossible for the traditional crushing equipment to crush the waste glass fiber reinforced plastics completely without any treatment. Therefore, we need special equipment to crush. Moreover, short of investment in recycling waste glass fiber reinforced plastics, glass fiber reinforced plastics production enterprises have no ability to achieve the rational use of waste glass fiber reinforced plastics.

Aiming at a series of problems of recycling and utilization of waste glass fiber reinforced plastics, we should start actions from both source and end to solve them. The government should enact relevant laws to prevent glass fiber reinforced plastics pollution and recycle the waste reasonably. The enterprises concerning glass fiber reinforced plastics production must take measures to recycle GFRP.

\section{Conclusion}

Chemical recycling method that decomposes waste glass fiber reinforced plastics into raw materials has important practical value for industrial production. But the method is accompanied by extortionate cost, which limits it applications. However, with more and more concerns and efforts on environmental pollution problems, chemical recycling certainly has a bright prospect. Using physical recycling and chemical recycling in combination may be a viable way to solve the problem.

Recycling and utilization of waste glass fiber reinforced plastics is a worthwhile work which should be added to the agenda as soon as possible. The recycling work can be synchronized with waste plastics. It is quite necessary to develop economic and feasible processing methods according to the characteristics of glass fiber reinforced plastics to promote the recycling and utilization of waste glass fiber reinforced plastics.

\section{References}

1. Tian Zhengbo, arvin, Recycling and Utilization of waste glass fiber reinforced plastics [J]. Journal of copper engineering, 2011 (4) :34-37.

2. Liu Xinchang, Introduction to glass fiber reinforced plastics recycling [J]. Glass fiber reinforced plastics, 2013 (2) : 23-24.

3. Zi-qiang $\mathrm{Wu}, \mathrm{Gui}$-zhen $\mathrm{Fu}$, The recycling of waste glass fiber reinforced plastics $[\mathrm{J}]$. Journal of renewable resources research, 2012 (3) : 11-14.

4. Wang Yujie, Organic inorganic glass fiber reinforced plastics technology:question and answer [M]. Beijing: chemical industry press, 2001, 47.

5. George Marsh, Facing up to the recycling challenge [J]. Reinforced Plastices, 2001(9):22-26.

6. Pickering S J, Recycling technologies for thermoset composite materials:current status [C].Composite: Part A,2006,37(8): 1206-1215.

7. Ehsani M O, FRP super laminaes present unparalleled solutions to old problems [J]. Reinforced Plastics,2009,53(6):40-45.

8. Hong-mei Gao, Yong-feng Sun, long Yi, Thermosetting composites recycled material performance evaluation And applications [C]. FRP to the 15th national FRP/composite material academic conference proceedings, 2003:355-361. 